\title{
Safe use of immune checkpoint inhibitors in the multidisciplinary management of urological cancer: The European Association of Urology position in 2019
}

Marc-Oliver Grimm $^{\mathrm{a}, ~ *}$, Axel Bex ${ }^{\mathrm{b}}$, Maria De Santis ${ }^{\mathrm{c}}$, Börje Ljunberg ${ }^{\mathrm{d}}$, James W.F. Catto ${ }^{\mathrm{e}}$, Morgan Rouprêt ${ }^{\mathrm{f}}$, Syed Hussain ${ }^{\mathrm{g}}$, Joaquim Bellmunt ${ }^{\mathrm{h}}$, Tom Powles ${ }^{\mathrm{i}}$, Manfred Wirth ${ }^{\mathrm{j}}$, Hendrik Van Poppel ${ }^{\mathrm{k}}$

${ }^{a}$ Department of Urology, Jena University Hospital, Germany; ${ }^{b}$ Specialist Centre for Kidney Cancer, Royal Free London NHS Foundation Trust and UCL Division of Surgery and Interventional Science, London, UK; ${ }^{\mathrm{C}}$ Department of Urology, Campus Charité Mitte, Charité - Universitätsmedizin Berlin, Berlin, Germany; ${ }^{d}$ Department of Surgical and Perioperative Sciences, Urology and Andrology, Umeå University, Umeå, Sweden; ${ }^{~}$ Academic Urology Unit, University of Sheffield, Sheffield, UK; ${ }^{f}$ Academic Department of Urology, Sorbonne Université, GRC $n^{\circ} 5$, ONCOTYPE-URO, Hôpital Pitié-Salpêtrière, Assistance-Publique Hôpitaux de Paris, F-75013 PARIS, France; ${ }^{\mathrm{g}}$ Academic Unit of Clinical Oncology, University of Sheffield, Sheffield, UK; ${ }^{h}$ Harvard Medical School, Boston and Hospital del Mar Medical Research Institute, Barcelona, Spain; 'The Royal Free NHS Trust and Barts Cancer Institute, Queen Mary University of London, London, UK; 'Department of Urology, Medical Faculty Carl Gustav Carus, Technical University of Dresden, Dresden, Germany; 'Department of Urology, University Hospitals Leuven, Leuven, Belgium

*Corresponding author (Address \& contact details):

Prof. Dr. med. Marc-Oliver Grimm

Department of Urology

Jena University Hospital

Am Klinikum 1

07747 Jena

Tel.: +49-3641-9-329901

Fax: +49-3641-9-329902

marc-oliver.grimm@med.uni-jena.de 
DRAFT ABSTRACT (250 words max.)

Immune checkpoint inhibitors (ICI) are now used routinely to treat advanced or metastatic urothelial and renal cell carcinoma. Furthermore, multiple trials are currently exploring their role in the adjuvant, neo-adjuvant and non-invasive (e.g. high-grade non-muscle invasive bladder cancer) settings. Consequently, urologists are increasingly confronted with patients who are, have recently or will receive ICI therapy. The care of these patients is likely to be shared between urologists and medical oncologists with additional occasional support of other medical specialties. Therefore, it is important urologists have knowledge of immune-related side effects, their early diagnosis and clinical management. Here we provide advice on prevention, diagnosis and clinical management of the most relevant toxicities to strengthen the urologists' role in the multidisciplinary management in the new immunotherapy era.

Patient summary: Immune therapy is a common treatment for many patients with advanced cancer. We described common side effects of this treatment and advise how it is best prevented and managed.

Keywords (MeSH) (up to 10)

Immunotherapy; Antineoplastic Agents; Immunological; immune related toxicity; nivolumab; pembrolizumab; atezolizumab; avelumab; durvalumab; ipilimumab 


\section{Introduction}

Immune checkpoint inhibitors (ICI) targeting the programmed cell death protein (PD-1) / programmed cell death ligand (PD-L1) axis are widely used today in a growing number of cancer indications; including urothelial and renal cell carcinoma. Following their development as monotherapies, current treatment strategies use ICls combined with other immune therapies (dual checkpoint inhibition with PD-1 and cytotoxic T-lymphocyteassociated antigen (CTLA-4) antagonists), with tyrosine kinase inhibitors, or chemotherapies. $\mathrm{ICl}$ are being investigated in therapeutic indications usually headed by multidisciplinary teams, with urologists either actively involved or even heading such teams. Examples include the adjuvant setting in renal cell carcinoma (RCC) or urothelial carcinoma (UC), or neoadjuvant treatment prior to cystectomy for bladder carcinoma as well as high-grade nonmuscle invasive bladder carcinoma. Therefore, urologists need to be well informed about the basic principles, current indications and special features of $\mathrm{ICl}$ therapy.

$\mathrm{ICl}$ are associated with a specific spectrum of side effects, namely immune-related adverse events (irAE). This spectrum differs from toxicities known for kinase inhibitors or cytotoxic drugs. The incidence of irAE varies, depending on the immune checkpoint that is targeted and the combination that is being used. As for any treatment modality, gains in efficacy must be balanced against the rates and severity of side effects. As delays in diagnosis and management might result in symptom worsening and further complications, clinicians prescribing $\mathrm{ICl}$ or supervising patients under or after $\mathrm{ICl}$ therapy shall be well trained to identify irAE promptly and monitor patients adequately.

This EAU position paper reviews the current status of $\mathrm{ICl}$ in urological cancers and provides recommendations for their safe use. This work provides an overview on common and relevant irAE that require urologists' particular attention; expert statements on the diagnosis and clinical management of irAE are provided as well.

\section{Patient selection}

Routine clinical use of $\mathrm{ICl}$ in urological tumors depends on country based approval and reimbursement status. Three ICI that act on the PD-1/PD-L1 pathway (atezolizumab, nivolumab and pembrolizumab) are approved for the use in advanced or metastatic UC and/or RCC as summarized in Table 1. For advanced RCC, nivolumab is also approved for use in combination with ipilimumab, an ICl targeting CTLA-4 $\left[{ }^{1}\right]$. Detailed staging and consideration of prior treatment sequence for advanced disease is essential to decide on patients' eligibility for ICl therapy. Additional immune biomarker testing is recommended and even required, if e.g. a use in untreated, cisplatin-ineligible urothelial cancer is considered. 
Table 1: PD-1/PD-L1 ICI for renal and urothelial cancer investigated and already reported in phase 3 randomized controlled trials

\begin{tabular}{|c|c|c|c|c|c|}
\hline Cancer & Indication & Atezolizumab & Avelumab & Nivolumab & Pembrolizumab \\
\hline \multirow[t]{2}{*}{$\mathrm{RCC}$} & $\begin{array}{l}\text { Untreated patients } \\
\quad \text { (1st line) }\end{array}$ & & $\begin{array}{c}\text { Avelumab } 10 \\
\text { mg/kg Q2W } \\
+ \\
\text { Axitinib } 5 \mathrm{mg} \\
\text { BID * }\end{array}$ & $\begin{array}{l}\text { Niv. } 3 \mathrm{mg} / \mathrm{kg}+ \\
\text { Ipilimumab } 1 \\
\mathrm{mg} / \mathrm{kg} \mathrm{Q} 3 \mathrm{~W} \text { x } 4 \\
\text { followed by Niv. } \\
3 \mathrm{mg} / \mathrm{kg} \mathrm{Q} 2 \mathrm{~W}^{* *}\end{array}$ & $\begin{array}{c}\text { Pembrolizumab } 200 \\
\text { mg Q3W } \\
+ \\
\text { Axitinib } 5 \mathrm{mg} \mathrm{BID} *\end{array}$ \\
\hline & $\begin{array}{l}\text { After prior VEGF- } \\
\text { targeted therapy }\end{array}$ & & & $\begin{array}{l}240 \mathrm{mg} \text { Q2W or } \\
480 \mathrm{mg} \text { Q4W }\end{array}$ & \\
\hline \multirow{2}{*}{$\mathbf{U C}$} & $\begin{array}{l}\text { Untreated (1st line), } \\
\text { Cisplatin-ineligible, } \\
\text { PD-L1 positive*** }\end{array}$ & $\begin{array}{c}1200 \mathrm{mg} \mathrm{Q} 3 \mathrm{~W} \\
(* * * \mathrm{IC} \text { score }>5 \%)\end{array}$ & & & $\begin{array}{c}200 \mathrm{mg} \text { Q3W } \\
(* * * \text { CPS-Score }>10)\end{array}$ \\
\hline & $\begin{array}{l}\text { After platinum- } \\
\text { based } \\
\text { chemotherapy }\end{array}$ & $1200 \mathrm{mg}$ Q3W & & $240 \mathrm{mg}$ Q2W & $200 \mathrm{mg}$ Q3W \\
\hline
\end{tabular}

* Request for approval filed

** Approved for intermediate/poor risk patients according to IMDC

*** Restricted indication (since summer 2018) to patients with high infiltrating immune cell (IC) status (atezolizumab) or high combined positive score (CPS) (pembrolizumab), both markers are correlates for PD-L1 positivity

Abbreviation: BID, ('bis in dies') twice per day; Niv, Nivolumab

\subsection{Renal cell carcinoma}

\subsubsection{Statement}

In advanced RCC, nivolumab monotherapy is a standard of care in patients who failed one or two prior lines of VEGF-targeted monotherapy.

The use of Nivolumab plus low dose Ipilimumab in treatment-naïve patients with advanced or metastatic clear-cell RCC of International Metastatic Renal Cell Carcinoma Database Consortium (IMDC) intermediate and poor risk is recommended by EAU guidelines $\left[{ }^{2}\right] . \mathrm{ICI}$ treatment should be given after a multidisciplinary decision by physicians experienced in this type of therapy. In patients who stopped ICI due to toxicity, a re-challenge with either drug should only be undertaken with expert guidance and support from a multidisciplinary team.

\subsubsection{Background}

For patients with advanced RCC with a clear-cell component, the EAU renal cancer guideline recommends the use of Nivolumab after one or two lines of VEGF-targeted therapy in metastatic RCC, based on results of a phase III trial [ $\left.{ }^{3}\right]$. Compared to Everolimus, a benefit in overall survival (OS: 25.0 vs. $19.6 \mathrm{mts}, \mathrm{HR}=0.73$ [98.5\% $\mathrm{Cl} 0.57-0.93$ ], $\mathrm{p}<0.002$ ), improved quality of life and fewer grade 3 or 4 adverse events were reported for Nivolumab. Strong evidence (grade 1B) also backs the recommendation for the EU/US approved use of Nivolumab plus low dose Ipilimumab in treatment-naïve patients with clear-cell metastatic RCC of IMDC intermediate and poor risk [ $\left.{ }^{4}\right]$. A phase 3 randomized controlled trial (RCT) of Atezolizumab plus Bevacizumab versus Sunitinib demonstrated a PFS benefit in patients with PD-L1 positive patients. However, a later interim analysis did not show an OS benefit and the 
respective EMA application was withdrawn (ref). Recent and partly preliminary data from phase 3 RCTs comparing the combination of the VEGFR-inhibitor tyrosine kinase inhibitor Axitinib with either the PD-L1 inhibitor Avelumab [ ${ }^{5}$ ], or the PD-1 antibody Pembrolizumab $\left[{ }^{6}\right]$ to the previous standard Sunitinib indicated consistent gains in efficacy across the overall trial population in treatment-naïve, advanced RCC with a clear cell component. Once the full data will become available in 2019, EU and US approval is likely for Pembrolizumab and Axitinib based on an OS benefit (OS benefit to be demonstrated for Avelumab plus Axitinib), introducing a new era in the front-line setting of metastatic RCC in which PD-1/PD-L1 ICI constitute the backbone of therapy, in combination with low dose Ipilimumab or with an antiVEGFR-directed tyrosine kinase inhibitor (TKI), respectively.

\subsection{Locally advanced unresectable / metastatic urothelial carcinoma}

\subsubsection{Statement}

PD-1 ICl are a standard treatment in patients after prior platinum-based chemotherapy (i.e. for second line therapy) [ ${ }^{\text {EAU Gdls. }}$. Among the approved ICI (Pembrolizumab, Atezolizumab, Nivolumab), available evidence (OS benefit) is currently favoring Pembrolizumab. Atezolizumab and Pembrolizumab may also be used in treatment-naïve, cisplatin-ineligible patients with PD-L1 positive tumors. Patients must be properly counseled about the potential risks and benefits as well as about the lack of randomized data comparing ICI to chemotherapy.

\subsubsection{Background}

Checkpoint inhibition with PD-1 and PD-L1 inhibitors has shown significant anti-tumor activity with acceptable toxicity and durable responses in patients with locally advanced and metastatic UC. PD-1 inhibitor pembrolizumab has shown a significant prolongation of OS (10.3 vs. $7.3 \mathrm{mts} ; \mathrm{HR}=0.73$ [95\% $\mathrm{Cl} 0.59-0.91], \mathrm{p}=0.004)$ in patients who had received prior platinum-containing chemotherapy $\left[{ }^{7}\right]$. Compared to standard-of-care chemotherapy, pembrolizumab also had a more favorable toxicity profile resulting in an improved quality of life $\left[{ }^{8}\right]$. Atezolizumab, a PD-L1 inhibitor, similarly showed favorable efficacy and reduced toxicities compared to chemotherapy, with no OS benefit observed $\left[{ }^{9},{ }^{10}\right]$. Nivolumab is the third ICI currently approved by the European Medicines Agency (EMA) in platinum pretreated advanced or metastatic UC patients, its recommendation for use is based on single-arm phase II trials [ ${ }^{11}$ ] (evidence level 1B for Pembrolizumab, 2A for Atezolizumab and Nivolumab).

Based on results from single-arm phase II trials, pembrolizumab and Atezolizumab are also available in the EU for use in UC patients that are not eligible for platinum-containing firstline therapy $\left[{ }^{12},{ }^{13}\right]$ (evidence level $2 \mathrm{~A}$ ): up to $50 \%$ of patients with locally advanced or metastatic UC are considered "unfit" for Cisplatin-based chemotherapy $\left[{ }^{14}\right]$. However, the EMA and the US Food and Drug Administration (FDA) recently restricted the use of both antibodies to patients with PD-L1 positive tumors. Different immunohistochemical evaluations (companion diagnostic test) need to be applied to test PD-L1 positivity for each of these antibodies (see 2.4. Biomarker).

Recently, encouraging results on PD-1 ICl in the neoadjuvant setting prior to cystectomy for muscle-invasive bladder cancer (MIBC) were reported (ref.). Ongoing phase 3 randomized trials focus on the neoadjuvant and adjuvant setting of MIBC. Furthermore, PD-1 ICI are explored in high-grade non-muscle invasive bladder cancer, e.g. for BCG refractory disease. 


\subsection{Prostate cancer}

\subsubsection{Statement}

$\mathrm{ICl}$ are not recommended for prostate cancer outside of clinical trials.

\subsubsection{Background}

In metastatic castration-resistant prostate cancer (mCRPC), results from two phase III trials investigating the use of Ipilimumab were disappointing. In Docetaxel-pre-treated $\left[{ }^{15}\right]$ as well as in chemotherapy-naïve patients $\left[{ }^{16}\right]$, CTLA4-blockade did not prolong survival, but resulted in significant toxicities. However, there were signs of activity of Ipilimumab including some exceptional cases with long-term remissions $\left[{ }^{17}\right]$. Evidence for PD-1 and PDL1 antagonists is currently limited to early clinical trials and small case series $\left[{ }^{18},{ }^{19}\right]$. Several phase II but also phase III trials in MCRPC are ongoing. Combinations with second-generation nonsteroidal antiandrogens are investigated as well as combinations with various PARPinhibitors (e.g. Olaparib, Rucaparib) or with chemotherapy (Docetaxel).

\subsection{Biomarker}

\subsubsection{Statement}

Prior to counseling cisplatin-ineligible, treatment-naïve patients with metastatic UC about ICI treatment options, immunohistochemical PD-L1 testing shall be performed to determine the Combined Positive Score (CPS)(for pembrolizumab) and/or the tumor-infiltrating immune cell (IC) score (for atezolizumab).

For RCC or previously treated metastatic UC, biomarker up-front testing is currently not mandatory. However, further biomarkers are under investigation that might become important to guide treatment decisions.

\subsubsection{Background}

The identification and validation of clinically useful biomarkers to guide therapeutic decisions for patient selection as well as for therapy monitoring of $\mathrm{ICl}$ is a critical issue across all cancer indications. PD-L1 immunohistochemistry, individual mutational analysis with TCGA (The Cancer Genome Atlas) RNA subtype correlation, determination of tumor mutational burden (TMB), tumor-infiltrating lymphocytes (TIL) counts, or immune cell gene expression (ICGE) profiling have been investigated pro- and retrospectively to identify potential biomarkers $\left[{ }^{20},{ }^{21},{ }^{22},{ }^{23}\right]$.

PD-L1 positivity, determined in terms of (variable) PD-L1 expression thresholds with different cut-offs, is the most comprehensively studied biomarker; its relevance as a biomarker has been highlighted by the development of several PD-L1 diagnostic tests, whose use is in the USA - foremost in non-small cell lung cancer - either mandatorily required (companion diagnostic TPS score $>50 \%$ for first line use of Pembrolizumab) for certain clinical uses, or at least recommended (complementary diagnostic) by the FDA to support physicians' informed decision-making $\left[{ }^{24}, 25,26,27\right]$. 
For RCC, testing of PD-L1 status yields conflicting results as predictive factor and assessment is, neither in the USA nor in the EU, mandatory. However, patients treated with the combination of Nivolumab plus low-dose Ipilimumab having PD-L1 positive tumors appear to benefit most with regard to overall survival (HR $0.45 \underline{\mathrm{vs}} .0 .73$ for PD-L1 negative tumors) and have a higher overall (58\% vs. $37 \%$ ) and complete response rate (16\% vs. $7 \%$ ), respectively. Of note, no benefit in terms of progression-free survival was observed for PD-L1 negative

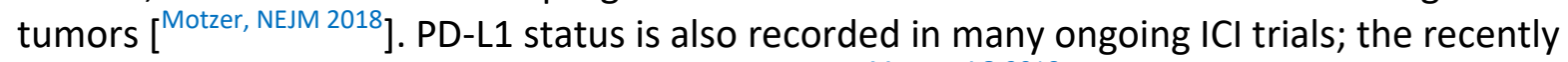

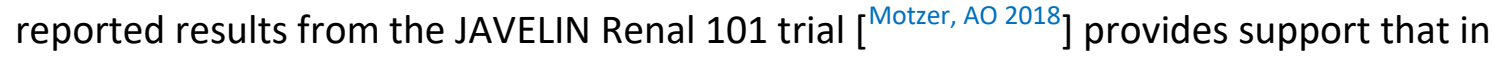
advanced, clear cell RCC therapy outcomes might be even more favorable in PD-L1 positive patients. However, due to the exploratory nature of PD-L1 tumor expression, the EAU renal cancer guideline does not recommend using PD-L1 as a predictive biomarker. As a prognostic factor, PD-L1 status may add to the IMDC prognostic criteria.

For the second-line use of Pembrolizumab, Nivolumab and Atezolizumab in locally advanced or metastatic UC - the same applies for the US-registered uses of Avelumab and Durvalumab in this UC setting - testing of PD-L1 expression is not required, too. While the Atezolizumab phase 2 trial indicated that response rate, progression-free survival and overall survival might be greater in patients with high PD-L1 expression, in the randomized phase 3 trial better outcomes were also observed in the chemotherapy arm resulting in no overall survival difference in the PD-L1 positive group [ ${ }^{\text {Powles, Lancet } 2018 ;}{ }^{28}$ ].

However, on June $1^{\text {st }} 2018$, the EMA restricted the first-line therapy labels of Pembrolizumab and Atezolizumab in Cisplatin-ineligible urothelial cancer due to efficacy issues identified in ongoing first line clinical trials, excluding now patients with low PD-L1 expression from its use $\left[{ }^{29}\right]$. The US FDA had alerted health care professionals and clinical trial investigators on 18 May 2018 with the same concerns $\left[{ }^{30}\right]$, which arose from interim analyses of the phase III trials, Keynote-361 and IMvigor $130\left[{ }^{31}, 32\right]$, and restricted both labels in August 2018. Since, treatment is limited to patients with tumors with either a combined (referring to tumor and immune cells) positive score (CPS) $\geq 10$ for Pembrolizumab or immune cell (IC) score $\geq 5 \%$ for Atezolizumab.

\section{Categorization and frequency of ICI therapy-related toxicities}

\subsection{Statement}

Side effects of ICI, namely irAE, may affect any organ system. Symptoms are frequently nonspecific, making their attribution difficult and the differential diagnosis between irAE and infection (e.g. pneumonitis versus pneumonia) imponderable. Urologists involved in the multidisciplinary treatment of renal, bladder and prostate cancer should be aware of irAE and know how to recognize and diagnose them. For the management of ICI therapy close multidisciplinary collaboration is mandatory.

\subsection{Background}

Treatment-related toxicities of $\mathrm{ICl}$ comprise two distinguishable sets of adverse drug reactions ( $A D R$ ): on one hand side effects generally associated with pharmacotherapy - i.e. due to absorption, distribution, metabolization and elimination processes, as e.g. hepatic or 
renal toxicities - on the other hand the partially novel immune-related $A E$ (irAE) which are well-known ICl class effects, caused by their direct impact on immune regulation.

The precise pathophysiology underlying irAE is still unknown but is thought to be related to the role that immune checkpoints play in immunologic homeostasis $\left[{ }^{33}\right]$. Unknown remains also the extent to which autoantibodies rather than autoreactive T-cells, contribute to irAE, or the role of cytokines which are thought to be involved in the pathophysiology of irAE. Current guidelines for side-effect assessment, such as Common Terminology Criteria for Adverse Events ${ }^{1}$ (CTCAE) are not specific to irAE reporting, and grading of irAE may be challenging $\left[{ }^{34}\right]$. Currently, irAE are described as AE which may differ in type, frequency or severity from AEs caused by non-immunotherapies: (i) which may require immunosuppression (e.g. corticosteroids) as part of their management; (ii) whose early recognition and management may mitigate severe toxicity; (iii) for which multiple event terms maybe used to describe a single type of $A E$, thereby necessitating the pooling of terms for full characterization $\left[{ }^{35}\right]$, an established definition of irAE is still missing.

Differentiation of $A E$ (i.e. treatment-related yes or no: and if yes, immune-related or not) requires careful differential diagnosis even of sometimes nonspecific and low-grade AE to distinguish whether tumor progression or organ-specific comorbidities or an ADR is the root cause of an AE. ADR not specifically related to immune reactions dominate, by their frequency, the adverse event reporting for ICl; their incidence (all grades), as summarized from actual summaries of product characteristics (SmPC) are listed in Table 2.

Table 2 - Very common and common ADR of checkpoint inhibitors authorised in the EU for use in urological cancers (frequencies reported according to current SmPC ${ }^{A}$ ). Listed are adverse reactions which are classified as 'very common' or 'common' for at least one drug regimen approved for use.

\begin{tabular}{|c|c|c|c|c|}
\hline $\begin{array}{l}\text { Adverse Reaction } \\
\text { (listed according to Standard Organ Class) }\end{array}$ & $\begin{array}{l}\text { Atezolizuma } \\
\text { b }\end{array}$ & $\begin{array}{l}\text { Nivoluma } \\
\text { b }\end{array}$ & $\begin{array}{l}\text { Pembrolizum } \\
\text { ab }\end{array}$ & $\begin{array}{l}\text { Nivolumab } \\
+ \\
\text { Ipilimumab }\end{array}$ \\
\hline \multicolumn{5}{|l|}{ Infections and infestations } \\
\hline $\begin{array}{l}\text { Upper respiratory tract infections / } \\
\text { pneumonia }\end{array}$ & $/ \%$ & 0 & $/ 0$ & 10 \\
\hline Neutropenia & 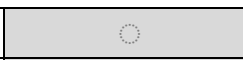 & $\square$ & $\mathbf{0}$ & \\
\hline Eosinophilia & e & $\boldsymbol{0}$ & $\boldsymbol{0}$ & 0 \\
\hline Anemia & e & $\square$ & O & \\
\hline Thrombocytopenia & 0 & $\square$ & 0 & $\mathbf{\square}$ \\
\hline $\begin{array}{l}\text { Infusion-related reaction / } \\
\text { hypersensitivity }\end{array}$ & 10 & $0 / 0$ & $0 /$ & $0 / 0$ \\
\hline Hypo-, hyperthyroidism / other ${ }^{\mathrm{B}} *$ & $\odot / \odot$ & $0 / 0$ & $0 / 0$ & $\mathbf{\square} / \mathbf{0}$ \\
\hline Decreased appetite & $\mathbf{E}$ & $\mathbf{O}$ & $\mathbf{0}$ & \\
\hline Dehydration & в & $\mathbf{0}$ & 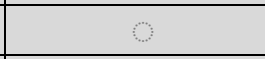 & 0 \\
\hline Hypokalemia / hyponatremia & $0 / 0$ & $\square / \mathbf{a}$ & $0 / 0$ & $\mathbf{a} \mathbf{\square}$ \\
\hline
\end{tabular}

\footnotetext{
${ }^{1}$ Common Terminology Criteria for Adverse Events (CTCAE) of the U.S. National Cancer Institute, V. 4.0: https://evs.nci.nih.gov/ftp1/CTCAE/CTCAE 4.03/Archive/CTCAE 4.0 2009-05-29 QuickReference 8.5x11.pdf
} 


\begin{tabular}{|c|c|c|c|c|}
\hline Headache & 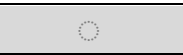 & - & - & $\mathbf{\square}$ \\
\hline Dizziness & a & - & - & - \\
\hline Peripheral neuropathy & . & O & O & O \\
\hline Uveitis * / blurred vision & 10 & $\mathbf{0} / \mathbf{0}$ & $\mathbf{0}$ & 0 \\
\hline Tachycardia & e & $\mathbf{0}$ & i & • \\
\hline Hypertension / hypotension & 10 & $0 / \%$ & $0 / \%$ & $0 / 1$ \\
\hline Dyspnea / Cough & 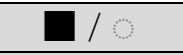 & $0 / 0$ & $0 / 0$ & - $/ 0$ \\
\hline Pneumonitis $* /$ pulmonary embolism & $0 / 1$ & $0 / 0$ & $0 / 0$ & 0 \\
\hline Hypoxia & - & 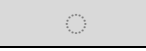 & 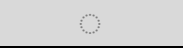 & . \\
\hline Diarrhea & $\mathbf{\square}$ & 口 & [ & 口 \\
\hline Nausea / Vomiting & $\bar{\square} / \mathbf{\square}$ & $\mathbf{\square} / \mathbf{0}$ & $\mathbf{\square} \mathbf{0}$ & $\mathbf{\square} / \mathbf{\square}$ \\
\hline Abdominal pain & 0 & 0 & $\bullet$ & 口 \\
\hline Stomatitis / colitis * / pancreatitis * & $/ 0 / 0$ & $\begin{array}{c}0 / 1 \\
0\end{array}$ & $10 / 0$ & $0 / 0 / 0$ \\
\hline Dry mouth / dysphagia & 10 & $\mathbf{0} /$ & - / & - / \\
\hline Constipation & . & - & - & - \\
\hline Lipase increased / amylase increased & $\mathbf{0} / \odot$ & $\mathbf{\square} / \mathbf{a}$ & 10 & 口/ \\
\hline Hepatitis * & $\mathbf{0}$ & $\mathbf{0}$ & $\mathbf{0}$ & ○ \\
\hline $\begin{array}{l}\text { Liver transaminases increased (ALT / } \\
\text { AST) }\end{array}$ & $0 / 0$ & $\mathbf{E} / \mathbf{\square}$ & $\bullet / \bullet$ & $\bar{\square} / \mathbf{\square}$ \\
\hline Rash $* /$ urticaria & - / & $\mathbf{0} / \mathbf{0}$ & - / & $\mathbf{\square} / 0$ \\
\hline Dry skin / pruritus & 1 & $\boldsymbol{0} / \mathbf{\square}$ & $\boldsymbol{\theta} / \mathbf{\square}$ & $\boldsymbol{0} / \mathbf{\square}$ \\
\hline Vitiligo / erythema & 10 & $0 / 0$ & $\bullet / \bullet$ & $0 / 0$ \\
\hline Alopecia & 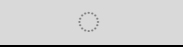 & 0 & $\mathbf{0}$ & 0 \\
\hline Arthralgia & [ & - & $\mathbf{0}$ & a \\
\hline Myositis * / arthritis & & 10 & $0 / 0$ & $\mathbf{0} / \mathbf{0}$ \\
\hline Muscoskeletal pain & - & 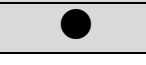 & $\bullet$ & $\mathbf{0}$ \\
\hline $\begin{array}{l}\text { Renal failure (including acute kidney } \\
\text { injury) }\end{array}$ & \% & - & \% & - \\
\hline Creatinine increased & . & - & - & 0 \\
\hline Pyrexia & $\mathbf{\square}$ & - & 0 & $\mathbf{\square}$ \\
\hline Influenza like illness / chills & $0 / 0$ & 10 & $\bullet / \bullet$ & 10 \\
\hline Fatigue & $\mathbf{n}$ & $\mathbf{\square}$ & $\mathbf{n}$ & E \\
\hline Asthenia & [ & 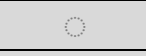 & - & 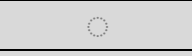 \\
\hline Oedema & 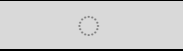 & - & 0 & - \\
\hline
\end{tabular}


${ }^{\mathbf{B}}$ includes (mainly): adrenal insufficiency, hypophysitis, thyroiditis

Legend: $\mathbf{\square}=$ Very common $(\geq 1 / 10$ patients $\{\geq 10 \%\}) ; \quad=$ common $(\geq 1 / 100$ and $<1 / 10$ patients $\{\geq 1 \%$ and $<10 \%\}) ; \mathbf{0}=$ uncommon $(\geq 1 / 1,000$ and $<1 / 100$ patients $\{\geq 0.1 \%$ and $<1 \%\}) ; \odot=\operatorname{rare}(\geq 1 / 10,000$ and $<$ $1 / 1,000$ patients $\{\geq 0.01 \%$ and $<0.1 \%\}) ; \circ=$ very rare $(<1 / 10,000$ patients $\{<0.01 \%\}) ;=$ not (yet) mentioned; frequency not yet determined; $*$ classified also as irAE Abbreviations: ADR, adverse drug reaction; irAE, immune-related adverse event; PIL, patient information leaflet; SmPC, summary of product characteristics

The overall incidence of adverse events (all causes and grades) in clinical trials of inhibitors of the PD-1/PL-L1 axis was $67.6 \%$, severe (grade 3-4 according to CTCAE) events occurred in $11.4 \%$ of patients, but these rates were lower than the rates in the chemotherapy control arms (82.9\% and $35.7 \%$, respectively) $\left[{ }^{36}\right]$. The most frequent adverse drug reactions (ADRs) are fatigue (31.8\%), diarrhea (18.5\%), arthralgia (12.4\%), back pain (10.9\%), according to recent meta-analysis $\left[{ }^{37}\right]$. The incidence of rash, observed with PD-1/PD-L1 inhibitors as well as with several tyrosine kinase inhibitors, meets with $10.3 \%$ also the WHO criteria for 'very

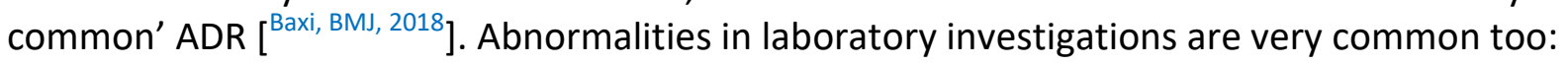
reported are increases of AST/ALT, hypokalemia, hyponatremia, or increased alkaline phosphatase, creatinine, lipase and amylase. Table 2 that lists all very common or common ADR mentioned in current EU prescribing information texts, mirrors these data from metaanalyses.

The overall incidence of treatment-related irAE, assessed though meta-analysis of 46 trials of PD-1 / PD-L1 inhibitors reporting 13,000 patients, is $26.8 \%$; severe irAE occur in $6.1 \%$ of patients, the incidence of therapy-related death is $<0.2 \%\left[{ }^{38}\right]$. Most frequent irAE (of any grade) are - both common - hypothyroidism (5.6\%) and pneumonitis (2.2\%); colitis (0.7\%), hypophysitis $(0.3 \%)$, and hepatitis $(0.2 \%)$ are uncommon [ ${ }^{\text {Baxi, BMJ } 2018}$ ]; the only common severe irAE is pneumonitis (1.4\%); severe colitis $(0.5 \%)$, hypophysitis $(0.2 \%)$, hyperthyroidism $(0.2 \%)$ and hepatitis $(0.1 \%)$ are uncommon [ ${ }^{\text {Baxi, BMJ } 2018}$ ]. The incidences generally match those reported in the EU prescription information texts, although differences manifest, mainly due to the grouped coding of several symptoms within a given irAE. Hyperthyroidism is also considered to constitute a common irAE (incidence 1.7-3.5 \%). Further uncommon events (0.1.-1.0\%) are adrenal insufficiency, type I diabetes mellitus, pancreatitis or nephritis; neurological ADR as Guillain-Barré syndrome or meningitis are uncommon too; other irAE as myasthenic syndrome, encephalitis or myocarditis occur rarely (incidence $<0.1 \%)$.

Compared to ADR rates in comparator arms of clinical trials (phase II-III) of PD-1/PD-L1 inhibitors, rates of irAE are increased for $\mathrm{ICl}$; of the more general ADR related to immune activation, only the rates of rash and associated pruritus are significantly increased for ICI

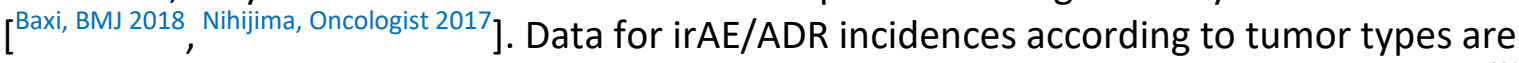
inconclusive so far; however, incidences of particular irAE vary across different cancers [ ${ }^{\text {Wang, }}$ Front Pharmacol 2017 ]. One review reported that arthritis and myalgia were more frequent in melanoma patients compared with RCC where pneumonitis was more prevalent $\left[{ }^{39}\right]$. Compared to PD-1 monotherapy, incidences of ADR and irAE are clearly augmented for PD1/CTLA-4 combined immune checkpoint blockade (Table 2) [ ${ }^{\mathrm{Khoja}, \mathrm{AO}} 2017,40,41$ ]; the rates of certain irAE augment substantially (colitis, pneumonitis, increases in transaminases and lipases) - colitis, rash and hypophysitis are more frequent with CTLA-4 than with PD-1 monotherapy, respectively [ Hassel, CTR 2017. El Osta, CROH 2017 ].

\section{Clinical diagnosis and management of ICI therapy-related major toxicities}


Five organ systems are frequently affected by ICI ADRs: Skin with exanthema and pruritus, liver with hepatitis, colon with diarrhea/colitis, lung with pneumonitis, and the endocrine systems. In order to identify irAEs as early as possible patients should regularly be asked for skin, bowel and/or pulmonary symptoms. Regular lab analyses should include liver and pancreas enzymes as well as creatinine since irAEs at the respective organs do not result in early symptoms. Furthermore, TSH should be closely monitored to identify hypo- or hyperthyreoidism. In case of unspecific symptoms and/or deterioration an irAE of the endocrine system should be rules out by analysis of TSH, LH, FSH, ACTH, cortisol, prolactin, and either estradiol or testosterone. The diagnosis of an irAE requires exclusion of other causes of the respective signs or symptoms, e.g. in case of diarrhea/colitis by stool culture or hepatitis serology and liver ultrasound (cholestasis, progression of liver metastasis) for rising transaminases. Early involvement of other relevant disciplines is recommended in order to facilitate optimal management of irAEs.

For the overall management of irAE, which are predominantly inflammatory reactions, interruptions of therapy or therapy discontinuations are measures of choice. Generally, in case of grade 4 irAE therapy discontinuation is recommended in line with systemic corticosteroid therapy, for grade 2 irAE, interruptions of therapy plus corticosteroid use are recommended, for grade $1 \mathrm{irAE}, \mathrm{ICl}$ therapy can usually be continued. Drug manufacturers' recommendations for the management of grade 3 irAE are heterogenous, the official recommendations for the clinically most relevant ${ }^{2}$ irAE are displayed in Figure 1 . Dose reductions/modifications are generally not recommended for $\mathrm{ICl}$.

For the general adverse events related to immune activation, consensus recommendations provide guidance in relation to the clinical management of fatigue $\left[{ }^{42},{ }^{43}\right]$, diarrhea $\left[{ }^{44}\right]$, nausea and vomiting $\left[{ }^{45}\right]$, infusion-related reactions $\left[{ }^{46}\right]$, pain $\left[{ }^{47}\right]$, or cardiotoxicities $\left[{ }^{48},{ }^{49}\right]$. More specific recommendations for the management of immunotherapy-induced toxicities are provided in a specific, novel ESMO Clinical Practice Guideline $\left[{ }^{50}\right]$; for the United States, similar guidance has been provided by the ASCO $\left[{ }^{51}\right]$. For the clinically prevailing irAE, specific recommendations for their diagnosis and clinical management are given in the subsequent text chapters.

\footnotetext{
${ }^{2}$ i.e. frequency, severity and complexity of event
} 


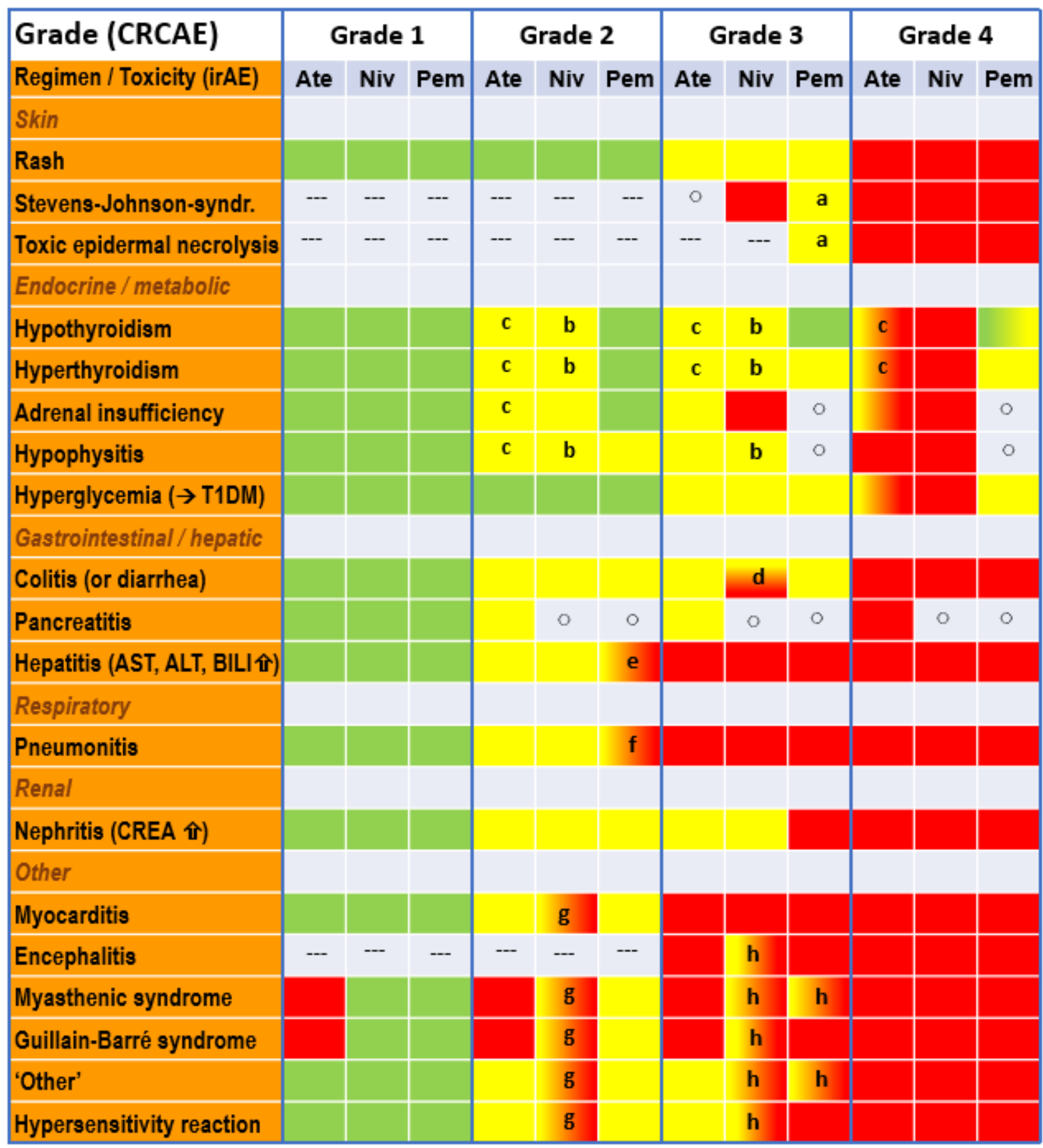

Legend: $---=$ AE not defined at the given grade; $\circ=$ no advice (yet), AE not (yet) mentioned in SmPC

a withhold, if ADR is suspected

b if symptomatic; therapy to be restarted once symptoms resolved (in presence of hormone replacement therapy)

c therapy might be resumed if symptoms are controlled \& TSH levels / thyroid function improves

d nivolumab monotherapy: withhold; nivolumab + ipilimumab: permanently discontinue

${ }^{e}$ permanently discontinue in case of liver metastasis with baseline grade 2 elevation of AST/ALT or lasting AST/ALT

${ }^{f}$ permanently discontinue therapy, if recurrent grade 2

$\mathbf{g}_{\text {permanently discontinue therapy, if persisting grade } 2}$

${ }^{\mathrm{h}}$ permanently discontinue if recurrent grade 3

Fig. 1 irAE type-/severity-dependent recommendations for treatment modifications of ICI therapy (assessment based on drug manufacturers' current prescribing information texts according to Table 2) 


\section{1. $\quad$ Skin and mucosal toxicity}

\subsubsection{Statement}

Rash and pruritus are the clinically most relevant dermatological side effects, which are reversible and clinically well manageable; their predictive value for response/survival requires clarification in larger studies. For CTC-AE grading estimate the body surface area affected using the "rule of 9" (known from burns). Urologists should consult a dermatologist in case of persisting or recurrent grade 3 ( $>30 \%$ of body surface area) toxicity.

\subsubsection{Background}

Very common skin toxicities include itching (pruritus) and associated rash, often in maculopapular form, and vitiligo (Table 2), the latter most often in melanoma patients [ ${ }^{52}$ ]. Wide-spread rash (exanthema) may occur at the trunk and/or extremities; treatment modalities include the use of topical corticosteroids (e.g. hydrocortisone cremes 1\%), or with urea or glycerine containing, moisturizing cremes or lotions. For continued itching, oral, nonsedative, systematic $\mathrm{H} 1$-antihistaminics might be used. Regular examinations prior and during $\mathrm{ICl}$ therapy should rule out skin problems of other aetiology, such as an infection, vasculitis, or contact dermatitis. The association of dermatological $\mathrm{AE}$ and $\mathrm{ICI}$ response or survival has been investigated, but its predictive value remains uncertain $\left[{ }^{53}\right]$.

For severe rash, treatment interruption (grade 3) or permanent discontinuation (grade 4) of $\mathrm{ICl}$ therapy is recommended (Fig. 1) and patients should immediately be placed under a dermatologist's supervision: this applies particularly, if severe skin reactions as StevensJohnson syndrome or toxic epidermal necrolysis are suspected or clinically manifest. Treatment consists of intravenous (i.v.) (methyl)prednisolone 1-2 mg/kg with slow tapering and switching to oral therapy when toxicity resolves to normal [ ${ }^{\text {Haanen, } \mathrm{AO} 2018}$ ].

\subsection{Endocrinological and metabolic toxicity}

\subsubsection{Statement}

Thyroid gland disorders are common side effects of $\mathrm{ICl}$, with 5-10\% of all patients affected. Narrow monitoring of TSH and a detailed hormone analysis (ACTH, LH, FSH, prolactin, cortisol, estradiol/testosterone) for otherwise unspecific symptoms or deterioration are required. The onset of immune related endocrinopathies is slow, their resolution may last for weeks and is not always reversible. Patients should be informed adequately prior to initiation of treatment that occurrence of endocrinopathies may result in long lasting or even permanent hormone replacement therapy. In case of suspected endocrinopathy other than hypo-/hyperthyreosis the patient should be referred early to a specialist with experience in the management of immune related endocrinopathies.

\subsubsection{Background}

$\mathrm{ICl}$-related immune endocrinopathies include commonly thyroid gland disorders (hypothyroidism, less frequently are hyperthyroidism or thyroiditis). Adrenal insufficiency is a common disorder too, hypophysitis is a rather uncommon event (Table 2). Compared to PD-1 monotherapy, endocrine toxicities are more frequent under combined immune 
checkpoint blockade $\left[{ }^{\text {Hassel, CTR } 2017}\right.$ ]. Due to their unspecific and often complex symptoms, the diagnostic approach might be challenging $\left[{ }^{54}\right]$.

The pathogenesis of thyroid disorders arising from ICI therapy is not yet well understood [Postow, NEJM 2018 , Haanen AO 2018]. Regular controls of thyroid stimulating hormone (TSH) - if repeatedly elevated or decreased or if a thyroid dysfunction is suspected, fT3, fT4 and cortisol should be measured as well - are helpful to diagnose hypo- or hyperthyroidism: these toxicities occur rather late after therapy start and resolve more slowly than other immune-related toxicities [ ${ }^{55}$, Hassel CTR ${ }^{2017}$ ]. Substitution with thyroid hormone (L-thyroxin, starting dose $50 \mathrm{mg}$ ) should be considered, if hypothyroidism is diagnosed. Mild and asymptomatic hyperthyroidism may be initially observed and might eventually turn into hypothyroidism. However, in symptomatic patients beta-blockers might be started [ Haanen, AO ${ }^{2018}$ ], the interruption of ICI therapy until recovery from symptoms is generally SmPC recommended for CTCAE of grade 3 (Fig. 1).

Adrenal insufficiency may manifest with diffuse symptoms, sometimes mild to moderate but similar to sepsis or an adrenal crisis $\left[{ }^{56}\right]$. The disorder might also develop following a (partial) insufficiency of the pituitary gland and therefore requires a differential diagnosis, whether the adrenal gland is affected or a hypophyseal insufficiency is suspected. When symptoms ameliorate, the use of hydrocortisone has been recommended to avoid the additional use of fludrocortisone as mineral corticoid replacement $\left[{ }^{57}\right]$. As in case of the above stated corticoid substitutions, an endocrinologist should be consulted to supervise/optimize substitution. The differential diagnosis of hypophysitis may require control of cortisol, adrenocorticotropic hormone (ACTH), luteinizing hormone ( $\mathrm{LH})$, follicle stimulating hormone (FSH), TSH, prolactin and - gender-dependent - estradiol or testosterone; magnetic resonance tomography (MRT) of the brain might confirm a swollen or enlarged pituitary gland. High-dose corticosteroids should be given in cases of headache or neurological problems; ICl therapy should be interrupted or even terminated from grade 2 symptoms onwards (Fig. 1): this irAE may result in continuous hormone (hydrocortisone) replacement therapy $\left[{ }^{58}\right]$.

Endocrine side effects are reversible in approximately half of all patients with thyroid or pituitary gland side effects, hence requiring often lasting hormone replacement therapy (HRT). Therefore, all patients shall be informed upfront about this potential, aggravating consequence of $\mathrm{ICl}$ therapy.

Type I diabetes mellitus, but also diabetes insipidus, are uncommon to rare side effects, advice is given to regularly monitor blood glucose levels, particularly if patients report polydipsia or polyuria [ ${ }^{\mathrm{Hassel}}$, CTR 2017 , Haanen, AO ${ }^{2018}$ ]. In severe cases, patients may develop ketoacidosis $\left[{ }^{59}\right]$ that should be treated according to established guidelines. Patients developing diabetes may require insulin substitution; in metabolically stable patients the ICI therapy may be restarted $\left[{ }^{60}\right.$, Haanen, AO 2018$]$.

\subsection{Gastrointestinal and hepatic toxicity}

\subsubsection{Statement}

To detect toxicities early, urologists should train and advise their patients to report any suspicious gastrointestinal and bowel symptoms directly to them; regarding hepatic irAE, narrow monitoring of liver transaminases and bilirubin is a key prerequisite.

\subsubsection{Background}


Like for skin and endocrine toxicities, certain gastrointestinal side effects are very common (diarrhoea, nausea, vomiting). Therapy-induced inflammation reactions under monotherapy are common to uncommon (Table 2 ), the routine monitoring should encompass events like stomatitis, colitis and pancreatitis as well as hepatitis $\left[{ }^{61}\right]$. Diarrhoea, although a rather unspecific adverse reaction and very frequently observed with chemotherapy or tyrosine kinase inhibitor therapy too, is however categorized as an irAE: its onset and resolution is equated in the official prescribing information with the onset and resolution of colitis, the most frequent severe gastrointestinal ADR of ICI therapy. Diagnostic work-up of colitis symptoms as diarrhoea, mucus or blood in stool, abdominal pain or change in bowel habits should include microbiological examination of stool to exclude pathological intestinal germs. Therapy of mild to moderate symptoms of colitis include therapy withhold beginning at CTCAE grade 2 and start of oral corticosteroid therapy: from grade 2 symptoms upwards, a colonoscopy should be considered. For combined immune checkpoint blockade, permanent therapy discontinuation is recommended for grade 3 or higher (Fig. 1); similarly, ICI monotherapy should be stopped after a first episode of grade 4 colitis and/or diarrhoea. In case of grade 3 diarrhoea or colitis or in case of remaining symptoms after ICl withdrawal, the i.v. application of corticosteroids is recommended without further delay. Diarrhoea and colitis are more frequent and occur earlier with CTLA-4 antibodies than with PD-1 or PD-L1

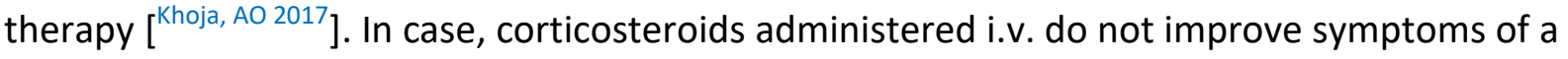
(moderate to) severe colitis, immune suppression should be escalated by using infliximab in

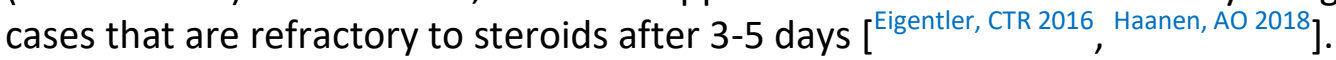
Increased lipase and amylase as well as bowel pain or vomiting may indicate moderate to severe forms of pancreatitis, which is commonly seen with combined anti-CTLA-4 plus PD-1 $\mathrm{ICI}$ therapy (Table 2). Pancreatitis as well as small bowel enterocolitis that may be visible through computer tomography (CT): if confirmed, discontinuation of ICI therapy and initiation of immunosuppression treatment is recommended in symptomatic patients with severe inflammation reactions (Fig. 1) [ ${ }^{\mathrm{Haanen}, \mathrm{AO} 2018}$ ]. However, treatment may be continued in cases of asymptomatic increases of amylase and lipase up to grade 3.

The narrow monitoring of serum transaminases (AST, ALT) and bilirubin is key to detect immune-related hepatitis and should be carried out prior to each treatment cycle $\left[{ }^{62}\right]$. Loss of appetite, nausea and vomiting, fatigue, icterus or frequent hematomas are other, unspecific events. As hepatitis is a diagnosis by exclusion, other causalities - particularly infections including viral hepatitis - have to be ruled out [ Haanen, AO 2018, Foller, Urologe 2017]. Liver sonography to exclude cholestasis or tumor progression and liver biopsy may be considered in assisting in the differential diagnosis of more severe hepatic side effects [ ${ }^{\text {Eigentler, CTR }{ }^{2017} \text { ]. }}$ Treatment of hepatitis includes the use of corticosteroids and depending, on severity, additive immunosuppressant agents as e.g. mycophenolate mofetil (as infliximab is hepatotoxic), if there is no response to corticosteroids within 2-3 days. ICI therapy should be withheld: this is recommended already, if transaminases or bilirubin reach CTC AE grade 2 (Fig. 1). For hepatitis grade 3 , all drug manufacturers recommend to permanently discontinue $\mathrm{ICl}$ therapy.

\subsection{Pulmonary toxicity}

\subsubsection{Statement}

Pneumonitis, the only severe irAE of common frequency in PD-1 ICl monotherapy (i.e. in $>1 \%$ of patients), has been the ADR associated with the highest number of fatal outcomes in 
clinical trials and routine use. Urologists should carefully monitor any pulmonary symptoms during or after $\mathrm{ICl}$ therapy and start differential-diagnostic work up (e.g. high resolution thoracic $\mathrm{CT}$ ) immediately in case of suspected pulmonary inflammation reactions.

\subsubsection{Background}

Pneumonitis is one of the most common irAE and the only severe irAE of common frequency (1.4\%) [ ${ }^{\text {Baxi, BMJ } 2018}$ ], numerous cases with a fatal outcome are reported (Table 1) $\left[{ }^{63},{ }^{64}\right]$. Hence, any pulmonary symptoms during ICl therapy should be monitored carefully: in case of upper airway infections, cough, hypoxia or dyspnea, use of a high resolution thoracic CT shall be considered to exclude pneumonitis. Ideally, an infection should be ruled out by bronchoscopy, especially in case of suspected grade 2 or greater pneumonitis.

After diagnosis corticosteroid therapy should start immediately with close lung function and blood gas control, thoracic X-ray is required in short intervals to control clinical course of pneumonitis. The exclusion of infection allows to introduce immunosuppressive therapy more safely, as such medication increases the chance of opportunistic infections [ ${ }^{\text {Haanen, AO }}$ ${ }^{2018}$ ]. However, if the differential diagnosis between pneumonitis and pneumonia remains uncertain high dose corticosteroids and antibiotics should be applied simultaneously upfront.

Higher grade pneumonitis leads to permanent discontinuation of IC therapy; one drug manufacturer recommends therapy discontinuation already in case of recurrent grade 2 pneumonitis (Fig. 1). In severe cases, additional non-steroidal immune suppression, e.g. with mycophenolate mofetil, should be considered. Corticosteroids should be tapered over 4-6 weeks (or even more) after recovery. For prophylaxis of opportunistic infections during this time, use of trimethoprim and sulfamethoxazole (e.g. $3 \times$ weekly) has been recommended [ Haanen, AO 2018; Foller, Urologe 2017].

\subsection{Renal toxicity}

\subsubsection{Statement}

Routine clinical chemistry (serum natrium, potassium, creatinine and urea) should be monitored during and after ICl therapy to monitor for renal dysfunctions.

\subsubsection{Background}

Cases of renal dysfunction are common under ICl therapy, usually indicated by an asymptomatic increase in creatinine: the incidence is higher with the combination of

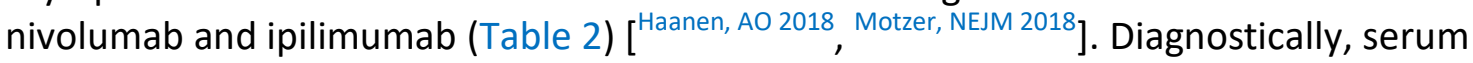
natrium, potassium, creatinine and urea should be monitored during $\mathrm{ICl}$ therapy and urinalysis (e.g. proteinuria ?) be performed in case of creatinine rise $\left[{ }^{65}, 66\right]$. However, histologically proven cases with nephritis are rare. Therefore, other causes of renal function deterioration (e.g. exsiccosis) should be excluded and renal biopsy be considered prior to start of corticosteroid therapy for potential immune related renal inflammation or damage. Beginning with creatinine elevations of grade 2 or higher, therapy should be withheld; for a grade 3 increase, certain drug manufacturers recommend stopping $\mathrm{ICl}$ therapy permanently (Fig. 1).

\subsection{Cardiac toxicity}




\subsubsection{Statement}

Be aware about the rare, but potentially life-threatening irAE that may result from ICI. In case of doubt, consult a cardiologist early.

\subsubsection{Background}

Immune-related cardiovascular toxicities are rare - however higher with the combination of nivolumab plus ipilimumab - but can be life-threatening and have caused fatalities, they deserve special attention and early consultation with a cardiologist [ ${ }^{\text {Hassel, CTR } 2017}$ ]. Onset of cardiotoxicity may occur early during treatment, with nonspecific symptoms such as fatigue or hypotension, or may occur as acute heart failure directly. Clinical symptoms and elevated creatinine kinase should prompt further diagnostic modalities including echocardiography or cardiac MRT, as well as cardiac biopsy. High-dose corticosteroids were successful in some patients, but the course was fatal in others [ ${ }^{\text {Haanen, } A O}{ }^{2018}$ ]. Drug manufacturers recommend to permanently discontinue ICI therapy in case of myocarditis with CTCAE grade $\geq 3$, or even in case of persisting grade 2 toxicity (Fig. 1).

\subsection{Neurological toxicity}

\subsubsection{Statement}

Neurological side effects are rare but might result in serious outcomes for patients; in case of onset, early therapy interruption and permanent discontinuation for all severe events (grade 3 and higher) is recommended.

\subsubsection{Background}

Neurological events are rare and may be present in form of encephalitis, Guillain-Barrésyndrome, myasthenic syndrome or myasthenia gravis $\left[{ }^{67}, 68,69\right]$ or other, very rare events [ Hassel, CTR ${ }^{2017}$ ]; some were just recently identified through EMA routine pharmacovigilance activities. Brain metastasis should be excluded by MRT in case of neurological symptoms. As laboratory and other examinations might differ from classical diagnostic procedures, a neurologist should be consulted in case of a suspected, neurological irAE. Treatment should include high-dose steroids as oral or i.v. prednisolone $(1-2 \mathrm{mg} / \mathrm{kg})$ and might be intensified through additional, immunosuppressive measures. Permanent discontinuation of ICl therapy is generally recommended for grade 3 or higher neurological toxicities (Fig. 1).

\section{Conclusions}

Immunotherapy using ICl plays an important role for the treatment of patients with advanced urological cancers. In order to manage patients with $\mathrm{ICl}$ treatment safely urologists should be aware of the nature, diagnosis and treatment of immune-related AEs. Most toxicities affect the skin with rash and pruritus, gastrointestinal tract with hepatitis and colitis/diarrhea, endocrine system with thyroid gland disorders and the lung with pneumonitis. However, immune-related AEs may affect any organ system and should be considered in each patient with prior ICI treatment. Immune-related AEs should be graded 
according to CTC in order to decide about treatment interruption or discontinuation as well as the initiation of corticosteroid therapy. For urologists inexperienced with immunotherapy early referral upon suspected irAEs to specialist centres is strongly recommended. For the management of $\mathrm{ICI}$ therapy close multidisciplinary collaboration is mandatory. 


\section{References}

${ }^{1}$ Buchbinder EI, Desai A. CTLA-4 and PD-1 Pathways: Similarities, Differences, and Implications of Their Inhibition. Am J Clin Oncol. 2016 Feb;39(1):98-106.

${ }^{2}$ EAU Guidelines. Edn. Presented at the EAU Annual Congress Copenhagen 2018. ISBN 978-94-9267101-1. http://uroweb.org/guidelines/compilations-of-all-guidelines/

${ }^{3}$ Motzer RJ, Escudier B, McDermott DF, George S, Hammers HJ, Srinivas S, et al. Nivolumab versus Everolimus in Advanced Renal-Cell Carcinoma. N Engl J Med. 2015 Nov 5;373(19):1803-1813.

${ }^{4}$ Motzer RJ, Tannir NM, McDermott DF, Arén Frontera O, Melichar B, Choueiri TK, et al. Nivolumab plus Ipilimumab versus Sunitinib in Advanced Renal-Cell Carcinoma. N Engl J Med. 2018 Apr 5;378(14):1277-1290.

${ }^{5}$ Motzer RJ, Penkov K, Haanen JB, Rini BL, Albiges L, Campbell MT, et al. JAVELIN renal 101: A randomized, phase III study of avelumab + axitinib vs sunitinib as first-line treatment of advanced renal cell carcinoma (aRCC). Ann Oncol (2018) 29 (suppl. 8) mdy 424.036 https://doi.org/10.1093/annonc/mdy424.036

${ }^{6}$ MSD Press release: Merck's KEYTRUDA ${ }^{\circledast}$ (pembrolizumab) in Combination with Pfizer's Inlyta ${ }^{\circledR}$ (axitinib) Significantly Improved Overall Survival (OS) and Progression-free Survival (PFS) as First-Line Therapy for Advanced or Metastatic Renal Cell Carcinoma. https://investors.merck.com/news/pressrelease-details/2018/Mercks-KEYTRUDA-pembrolizumab-in-Combination-with-Pfizers-Inlyta-axitinibSignificantly-Improved-Overall-Survival-OS-and-Progression-free-Survival-PFS-as-First-Line-Therapyfor-Advanced-or-Metastatic-Renal-Cell-Carcinoma/default.aspx (Accessed 20 Dec 2018).

${ }^{7}$ Bellmunt J, de Wit R, Vaughn DJ, Fradet Y, Lee JL, Fong L, et al. Pembrolizumab as second-line therapy for advanced urothelial carcinoma. N Engl J Med. 2017 376:1015-26

${ }^{8}$ Vaughn DJ, Bellmunt J, Fradet Y, Lee JL, Fong L, Vogelzang NJ, et al. Health-related quality-of-life analysis from KEYNOTE-045: a phase III study of pembrolizumab versus chemotherapy for previously treated advanced urothelial cancer. J Clin Oncol. 2018 Jun 1;36(16):1579-1587.

${ }^{9}$ Rosenberg JE, Hoffman-Censits J, Powles T et al. Atezolizumab in patients with locally advanced and metastatic urothelial carcinoma who have progressed following treatment with platinum-based chemotherapy: a single-arm, multicentre, phase 2 trial. Lancet (2016) 387:1909-20

${ }^{10}$ Powles T, Durán I, van der Heijden MS, Loriot Y, Vogelzang NJ, De Giorgi U, et al. Atezolizumab versus chemotherapy in patients with platinum-treated locally advanced or metastatic urothelial carcinoma (IMvigor211): a multicentre, open-label, phase 3 randomised controlled trial. Lancet. 2018 Feb 24;391(10122):748-757. doi: 10.1016/S0140-6736(17)33297-X.

${ }^{11}$ Sharma P, Retz M, Siefker-Radtke A, Baron A, Necchi A, Bedke J, et al. Nivolumab in metastatic urothelial carcinoma after platinum therapy (CheckMate 275): a multicenter, single-arm, phase 2 trial. Lancet Oncol (2017) 388: 312-22.

${ }^{12}$ Balar AV, Castellano D, O'Donnell PH, Grivas P, Vuky J, Powles T, et al. First-line pembrolizumab in cisplatin-ineligible patients with locally advanced and unresectable or metastatic urothelial cancer (KEYNOTE-052): a multicentre, single-arm, phase 2 study. Lancet Oncol. 2017 Nov;18(11):1483-1492. doi: 10.1016/S1470-2045(17)30616-2.

${ }^{13}$ Balar AV, Galsky MD, Rosenberg JE, Powles T, Petrylak DP, Bellmunt J, et al. Atezolizumab as firstline treatment in cisplatin-ineligible patients with locally advanced and metastatic urothelial carcinoma: a single-arm, multicentre, phase 2 trial. Lancet. 2017 Jan 7;389(10064):67-76. doi: 10.1016/S0140-6736(16)32455-2

${ }^{14}$ Galsky MD, Hahn NM, Rosenberg J, Sonpavde G, Hutson T, Oh WK, et al. Treatment of patients with metastatic urothelial cancer "unfit" for Cisplatin-based chemotherapy. J Clin Oncol. 2011 Jun 10;29(17):2432-8.

${ }^{15}$ Kwon ED, Drake CG, Scher HI, Fizazi K, Bossi A, van den Eertwegh AJ, et al (CA184-043 Investigators). I I pilimumab versus placebo after radiotherapy in patients with metastatic castrationresistant prostate cancer that had progressed after docetaxel chemotherapy (CA184-043): a multicentre, randomised, double-blind, phase 3 trial. Lancet Oncol. 2014 Jun;15(7):700-12 
${ }^{16}$ Beer TM, Kwon ED, Drake CG, Fizazi K, Logothetis C, Gravis G, et al. Randomized, Double-Blind, Phase III Trial of Ipilimumab Versus Placebo in Asymptomatic or Minimally Symptomatic Patients With Metastatic Chemotherapy-Naive Castration-Resistant Prostate Cancer. J Clin Oncol. 2017 Jan;35(1):40-47.

${ }^{17}$ Cabel L, Loir E, Gravis G, Lavaud P, Massard C, Albiges L, et al. Long-term complete remission with Ipilimumab in metastatic castrate-resistant prostate cancer: case report of two patients. J Immunother Cancer. 2017 Apr 18;5:31.

${ }^{18}$ Graff JN, Alumkal JJ, Drake CG, Thomas GV, Redmond WL, Farhad M, et al. Early evidence of antiPD-1 activity in enzalutamide-resistant prostate cancer. Oncotarget. 2016 Aug 16;7(33):52810-52817.

${ }^{19}$ Redman JM, Steinberg SM, Gulley JL. Quick efficacy seeking trial (QuEST1): a novel combination immunotherapy study designed for rapid clinical signal assessment metastatic castration-resistant prostate cancer. J Immunother Cancer. 2018 Sep 18;6(1):91.

${ }^{20}$ Topalian SL, Taube JM, Anders RA, Pardoll DM. Mechanism-driven biomarkers to guide immune checkpoint blockade in cancer therapy. Nat Rev Cancer. 2016 May;16(5):275-87.

${ }^{21}$ Patil PD, Burotto M, Velcheti V. Biomarkers for immune-related toxicities of checkpoint inhibitors: current progress and the road ahead. Expert Rev Mol Diagn. 2018 Mar;18(3):297-305.

${ }^{22}$ Zhu J, Armstrong AJ, Friedlander TW, Kim W, Pal SK, George DJ, et al. Biomarkers of immunotherapy in urothelial and renal cell carcinoma: PD-L1, tumor mutational burden, and beyond. $\mathrm{J}$ Immunother Cancer. 2018 Jan 25;6(1):4. doi: 10.1186/s40425-018-0314-1.

${ }^{23}$ Melosky B, Chu Q, Juergens RA, Leighl N, lonescu D, Tsao MS, et al. Breaking the biomarker code: PD-L1 expression and checkpoint inhibition in advanced NSCLC. Cancer Treat Rev. 2018 Apr;65:65-77 ${ }^{24}$ Udall M, Rizzo M, Kenny J, Doherty J, Dahm S, Robbins P, et al. PD-L1 diagnostic tests: a systematic literature review of scoring algorithms and test-validation metrics. Diagn Pathol. 2018 Feb 9;13(1):12. doi: 10.1186/s13000-018-0689-9.

${ }^{25}$ Hirsch FR, McElhinny A, Stanforth D, Ranger-Moore J, Jansson M, Kulangara K, et al. PD-L1 Immunohistochemistry Assays for Lung Cancer: Results from Phase 1 of the Blueprint PD-L1 IHC Assay Comparison Project. J Thorac Oncol. 2017 Feb;12(2):208-222

${ }^{26}$ Tsao MS, Kerr KM, Kockx M, Beasley MB, Borczuk AC, Botling J, et al. PD-L1 Immunohistochemistry Comparability Study in Real-Life Clinical Samples: Results of Blueprint Phase 2 Project. J Thorac Oncol. 2018 Sep;13(9):1302-1311

${ }^{27}$ Rimm DL, Han G, Taube JM, Yi ES, Bridge JA, Flieder DB, et al. A Prospective, Multi-institutional, Pathologist-Based Assessment of 4 Immunohistochemistry Assays for PD-L1 Expression in Non-Small Cell Lung Cancer. JAMA Oncol. 2017 Aug 1;3(8):1051-1058.

${ }^{28}$ Rosenberg JE, Hoffman-Censits J, Powles T et al. Atezolizumab in patients with locally advanced and metastatic urothelial carcinoma who have progressed following treatment with platinum-based chemotherapy: a single-arm, multicentre, phase 2 trial. Lancet (2016) 387:1909-20.

${ }^{29}$ EMA Press release. EMA restricts use of Keytruda and Tecentriq in bladder cancer. [1 June 2018 EMA/364553/2018]

${ }^{30}$ FDA Drug Safety and Availability Alerts. FDA Alerts Health Care Professionals and Oncology Clinical $\underline{\text { Investigators about an Efficacy Issue Identified in Clinical Trials for Some Patients Taking Keytruda }}$ (pembrolizumab) or Tecentriq (atezolizumab) as Monotherapy to Treat Urothelial Cancer with Low Expression of PD-L1. [Alert 18 May 2018; update 20 June 2018]

${ }^{31}$ Powles T, Geschwend JE, Loriot Y, Bellmunt J, Geczi L, Vulsteke C, et al. Phase 3 KEYNOTE-361 trial: Pembrolizumab (pembro) with or without chemotherapy versus chemotherapy alone in advanced urothelial cancer. J Clin Oncol. 2017; 35(15) suppl, TPS4590

${ }^{32}$ Galsky MD, Grande E, Davis ID, De Santis M, Arranz Arija JA, Kikuchi E, et al. IMvigor130: A randomized, phase III study evaluating first-line (1L) atezolizumab (atezo) as monotherapy and in combination with platinum-based chemotherapy (chemo) in patients (pts) with locally advanced or metastatic urothelial carcinoma (mUC). J Clin Oncol 36, 2018 (suppl; abstr TPS4589) 
${ }^{33}$ Postow MA, Sidlow R, Hellmann MD. Immune-Related Adverse Events Associated with Immune Checkpoint Blockade. N Engl J Med. 2018 Jan 11;378(2):158-168. doi: 10.1056/NEJMra1703481.

${ }^{34}$ Chen TW, Razak AR, Bedard PL, Siu LL, Hansen AR. A systematic review of immunerelated adverse event reporting in clinical trials of immune checkpoint inhibitors. Ann Oncol. 2015 Sep;26(9):1824-9. doi: 10.1093/annonc/mdv182. Epub 2015 Apr 17.

${ }^{35}$ European Medicines Agency. Assessment report Opdivo (nivolumab). EMA/682492/2015, 24 Sep 2015. http://www.ema.europa.eu/docs/en GB/document library/EPAR - Assessment Report Variation/human/003985/WC500197950.pdf. Accessed: 5 Jul 2018.

${ }^{36}$ Nishijima TF, Shachar SS, Nyrop KA, Muss HB. Safety and tolerability of PD-1/PD-L1 inhibitors compared with chemotherapy in patients with advanced cancer: a meta-analysis. Oncologist. 2017 Apr;22(4):470-479. doi: 10.1634/theoncologist.2016-0419.

${ }^{37}$ Baxi S, Yang A, Gennarelli RL, Khan N, Wang Z, Boyce L, et al. Immune-related adverse events for anti-PD-1 and anti-PD-L1 drugs: systematic review and meta-analysis. BMJ. 2018 Mar 14;360:k793. doi: 10.1136/bmj.k793.

${ }^{38}$ Wang PF, Chen Y, Song SY, Wang TJ, Ji WJ, Li SW, Liu N, Yan CX. Immune-related adverse events associated with anti-PD-1/PD-L1 treatment for malignancies: a meta-analysis. Front Pharmacol. 2017 Oct 18;8:730. doi: 10.3389/fphar.2017.00730. eCollection 2017.

${ }^{39}$ Khoja L, Day D, Wei-Wu Chen T, Siu LL, Hansen AR. Tumour- and class-specific patterns of immunerelated adverse events of immune checkpoint inhibitors: a systematic review. Ann Oncol. 2017 Oct 1;28(10):2377-2385. doi: 10.1093/annonc/mdx286

${ }^{40}$ Hassel JC, Heinzerling L, Aberle J, Bähr O, Eigentler TK, Grimm MO, et al. Combined immune checkpoint blockade (anti-PD-1/anti-CTLA-4): evaluation and management of adverse drug reactions. Cancer Treat Rev. 2017 Jun;57:36-49. doi: 10.1016/j.ctrv.2017.05.003

${ }^{41}$ El Osta B, Hu F, Sadek R, Chintalapally R, Tang SC. Not all immune-checkpoint inhibitors are created equal: Meta-analysis and systematic review of immune-related adverse events in cancer trials. Crit Rev Oncol Hematol. 2017 Nov;119:1-12. doi:

10.1016/j.critrevonc.2017.09.002.

${ }^{42}$ Ripamonti Cl, Antonuzzo A, Bossi P, Cavalieri S, Roila F, Fatigoni S. Fatigue, a major still underestimated issue. Curr Opin Oncol. 2018 Jul;30(4):219-225

${ }^{43}$ Pearson EJ, Morris ME, McKinstry CE. Cancer-related fatigue: appraising evidence-based guidelines for screening, assessment and management. Support Care Cancer. 2016 Sep;24(9):3935-42.

${ }^{44}$ Bossi P, Antonuzzo A, Cherny NI, Rosengarten O, Pernot S, Trippa F, et al. Diarrhea in adult cancer patients: ESMO Clinical Practice Guidelines. Ann Oncol. 2018 Jun 21. doi: 10.1093/annonc/mdy145. [Epub ahead of print]

${ }^{45}$ Roila F, Molassiotis A, Herrstedt J, Aapro M, Gralla RJ, Bruera E, et al. 2016 MASCC and ESMO guideline update for the prevention of chemotherapy-and radiotherapy-induced nausea and vomiting and of nausea and vomiting in advanced cancer patients. Ann Oncol. 2016 Sep;27(suppl 5):v119-v133.

${ }^{46}$ Roselló S, Blasco I, García Fabregat L, Cervantes A, Jordan K; ESMO Guidelines Committee. Management of infusion reactions to systemic anticancer therapy: ESMO Clinical Practice Guidelines. Ann Oncol. 2018 May 5. doi: 10.1093/annonc/mdy158. [Epub ahead of print]

${ }^{47}$ Ripamonti CI, Santini D, Maranzano E, Berti M, Roila F; ESMO Guidelines Working Group. Management of cancer pain: ESMO Clinical Practice Guidelines. Ann Oncol. 2012 Oct;23 Suppl 7:vii139-54

${ }^{48}$ Zamorano JL, Lancellotti P, Rodriguez Muñoz D, Aboyans V, Asteggiano R, Galderisi M, et al. 2016 ESC Position Paper on cancer treatments and cardiovascular toxicity developed under the auspices of the ESC Committee for Practice Guidelines: The Task Force for cancer treatments and cardiovascular toxicity of the European Society of Cardiology (ESC). Eur Heart J. 2016 Sep 21;37(36):2768-2801. doi: 10.1093/eurheartj/ehw211. 
${ }^{49}$ Curigliano G, Cardinale D, Suter T, Plataniotis G, de Azambuja E, Sandri MT, et al. Cardiovascular toxicity induced by chemotherapy, targeted agents and radiotherapy: ESMO Clinical Practice Guidelines. Ann Oncol. 2012 Oct;23 Suppl 7:vii155-66

${ }^{50}$ Haanen JBAG, Carbonnel F, Robert C, Kerr KM, Peters S, Larkin J, Jordan K; ESMO Guidelines Committee. Management of toxicities from immunotherapy: ESMO Clinical Practice Guidelines for diagnosis, treatment and follow-up. Ann Oncol. 2018 Jun 15. doi: 10.1093/annonc/mdy162. [Epub ahead of print]

${ }^{51}$ Brahmer JR, Lacchetti C, Schneider BJ, Atkins MB, Brassil KJ, Caterino JM, et al. Management of Immune-Related Adverse Events in Patients Treated with Immune Checkpoint Inhibitor Therapy: American Society of Clinical Oncology Clinical Practice Guideline. J Clin Oncol. 2018 Jun 10;36(17):1714-1768. doi: 10.1200/JCO.2017.77.6385.

${ }^{52}$ Belum VR, Benhuri B, Postow MA, Hellmann MD, Lesokhin AM, Segal NH, et al. Characterisation and management of dermatologic adverse events to agents targeting the PD-1 receptor. Eur J Cancer. 2016 Jun; 60:12-25. doi: 10.1016/j.ejca.2016.02.010

${ }^{53}$ Hopkins AM, Rowland A, Kichenadasse G, Wiese MD, Gurney H, McKinnon RA, et al. Predicting response and toxicity to immune checkpoint inhibitors using routinely available blood and clinical markers. Br J Cancer. 2017 Sep 26;117(7):913-920.

${ }^{54}$ Sznol M, Postow MA, Davies MJ, Pavlick AC, Plimack ER, Shaheen M, et al. Endocrine-related adverse events associated with immune checkpoint blockade and expert insights on their management. Cancer Treat Rev. 2017 Jul;58:70-76. doi: 10.1016/j.ctrv.2017.06.002

${ }^{55}$ Eigentler TK, Hassel JC, Berking C, Aberle J, Bachmann O, Grünwald V, et al. Diagnosis, monitoring and management of immune-related adverse drug reactions of anti-PD-1 antibody therapy. Cancer Treat Rev. 2016 Apr;45:7-18. doi: 10.1016/j.ctrv.2016.02.003.

${ }^{56}$ Bornstein SR, Allolio B, Arlt W, Barthel A, Don-Wauchope A, Hammer GD, et al. Diagnosis and Treatment of Primary Adrenal Insufficiency: An Endocrine Society Clinical Practice Guideline. J Clin Endocrinol Metab. 2016 Feb;101(2):364-89. doi: 10.1210/jc.2015-1710.

${ }^{57}$ Grimm MO, Oppel-Heuchel H, Foller S. [Treatment with PD-1/PD-L1 and CTLA-4 immune checkpoint inhibitors: Immune-mediated side effects]. Urologe A. 2018 May;57(5):543-551. doi: 10.1007/s00120-018-0635-1.

${ }^{58}$ Solinas C, Porcu M, De Silva P, Musi M, Aspeslagh S, Scartozzi M, et al. Cancer immunotherapyassociated hypophysitis. Semin Oncol. 2018 Jun;45(3):181-186.

${ }^{59}$ Gauci ML, Laly P, Vidal-Trecan T, Baroudjian B, Gottlieb J, Madjlessi-Ezra N, et al. Autoimmune diabetes induced by PD-1 inhibitor-retrospective analysis and pathogenesis: a case report and literature review. Cancer Immunol Immunother. 2017 Nov;66(11):1399-1410. doi: 10.1007/s00262017-2033-8

${ }^{60}$ Foller S, Oppel-Heuchel H, Fetter I, Winkler Y, Grimm MO. [Adverse events of immune checkpoint inhibitors]. Urologe A. 2017 Apr;56(4):486-491. doi: 10.1007/s00120-017-0342-3

${ }^{61}$ Samaan MA, Pavlidis P, Papa S, Powell N, Irving PM. Gastrointestinal toxicity of immune checkpoint inhibitors: from mechanisms to management. Nat Rev Gastroenterol Hepatol. 2018 Apr;15(4):222234. doi: 10.1038/nrgastro.2018.14.

${ }^{62}$ Suzman DL, Pelosof L, Rosenberg A, Avigan MI. Hepatotoxicity of immune checkpoint inhibitors: An evolving picture of risk associated with a vital class of immunotherapy agents. Liver Int. 2018 Jun;38(6):976-987. doi: 10.1111/liv.13746.

${ }^{63}$ Khunger M, Rakshit S, Pasupuleti V, Hernandez AV, Mazzone P, Stevenson J, et al. Incidence of pneumonitis with use of Programmed Death 1 and Programmed Death-Ligand 1 inhibitors in nonsmall cell lung cancer: a systematic review and meta-analysis of trials. Chest. 2017 Aug;152(2):271281. doi: 10.1016/j.chest.2017.04.177

${ }^{64}$ Nishino M, Giobbie-Hurder A, Hatabu H, Ramaiya NH, Hodi FS. Incidence of Programmed Cell Death 1 inhibitor-related pneumonitis in patients with advanced cancer: a systematic review and meta-analysis. JAMA Oncol. 2016 Dec 1;2(12):1607-1616. doi: 
${ }^{65}$ Wanchoo R, Karam S, Uppal NN, Barta VS, Deray G, Devoe C, et al. Adverse renal effects of immune checkpoint inhibitors: a narrative rReview. Am J Nephrol. 2017;45(2):160-169. doi: 10.1159/000455014

${ }^{66}$ Rassy EE, Kourie HR, Rizkallah J, Karak FE, Hanna C, Chelala DN, et al. Immune checkpoint inhibitors renal side effects and management. Immunotherapy. 2016 Dec;8(12):1417-1425. doi: 10.2217/imt2016-0099

${ }^{67}$ Fellner A, Makranz C, Lotem M, Bokstein F, Taliansky A, Rosenberg S, et al. Neurologic complications of immune checkpoint inhibitors. J Neurooncol. 2018 May;137(3):601-609. doi: 10.1007/s11060-018-2752-5.

${ }^{68}$ Eldar AH, Chapman J. Guillain Barré syndrome and other immune mediated neuropathies: diagnosis and classification. Autoimmun Rev. 2014 Apr-May;13(4-5):525-30. doi: 10.1016/j.autrev.2014.01.033.

${ }^{69}$ Makarious D, Horwood K, Coward JIG. Myasthenia gravis: An emerging toxicity of immune checkpoint inhibitors. Eur J Cancer. 2017 Sep;82:128-136. doi: 10.1016/j.ejca.2017.05.041. 